\title{
Effect of packing on changes in erythrocyte osmotic fragility and malondialdehyde concentration in donkeys administered with ascorbic acid
}

\author{
Authors: \\ Folashade Olaifa ${ }^{1}$ \\ Joseph O. Ayo ${ }^{1}$ \\ Suleiman F. Ambali ${ }^{1}$ \\ Peter I. Rekwot ${ }^{2}$

\section{Affiliations:} \\ ${ }^{1}$ Department of Physiology \\ and Pharmacology, Ahmadu \\ Bello University, Nigeria \\ ${ }^{2}$ National Animal Production \\ Research Institute, Ahmadu \\ Bello University, Nigeria \\ Correspondence to: \\ Folashade Olaifa \\ Email: \\ folashadeakanmu@yahoo. \\ com \\ Postal address: \\ Department of Physiology \\ and Pharmacology, Ahmadu \\ Bello University, Nigeria, \\ 810000 \\ Dates: \\ Received: 11 Feb. 2012 \\ Accepted: 20 Aug. 2012 \\ Published: 05 Dec. 2012 \\ How to cite this article: \\ Olaifa, F., Ayo, J.O., Ambali, \\ S.F. \& Rekwot, P.I., 2012, \\ 'Effect of packing on changes \\ in erythrocyte osmotic \\ fragility and malondialdehyde \\ concentration in donkeys \\ administered with ascorbic \\ acid', Onderstepoort Journal \\ of Veterinary Research 79(1), \\ Art. \#413, 5 pages. \\ http://dx.doi.org/10.4102/ \\ ojvr.v79i1.413
}

Experiments were performed with the aim of investigating the effect of packing on erythrocyte osmotic fragility (EOF) and malondialdehyde (MDA) concentration in donkeys, and the effect of ascorbic acid (AA). Twelve apparently healthy donkeys raised under the traditional extensive system served as experimental subjects. Six donkeys administered orally with AA (200 mg/ $\mathrm{kg}$ ) and subjected to packing were used as experimental animals, whilst six others not administered with AA served as controls. Blood samples were collected pre- and post-packing from all the donkeys for the determination of MDA and EOF. At $0.3 \%$ Sodium Chloride $(\mathrm{NaCl})$ concentration, the percentage haemolysis was $93.69 \% \pm 2.21 \%$ in the control donkeys and the value was significantly $(P<0.05)$ higher than the value of $71.31 \% \pm 8.33 \%$, recorded in the experimental donkeys. The post-packing MDA concentration obtained in the control donkeys was $39.62 \mu \mathrm{mol} \pm 4.16 \mu \mathrm{mol}$, and was not significantly different $(P>0.05)$ from the value of $35.97 \mu \mathrm{mol} \pm 2.88 \mu \mathrm{mol}$ recorded in the experimental donkeys. In conclusion, the increase in haemolysis obtained in the donkeys suggested that packing induced oxidative stress, which was ameliorated by AA administration.

\section{Introduction}

It has been established that erythrocyte osmotic fragility (EOF) is a good indicator of stress (Adenkola et al. 2010; Asala et al. 2011; Hesta et al. 2008). Changes in the EOF occurring during physical exertion such as in exercise in the equine are important indicators of intravascular haemolysis (Hanzawa \& Watanabe 2000). Erythrocyte osmotic fragility has been used to evaluate stress due to transportation by road in pigs (Adenkola \& Ayo 2009; Asala et al. 2011) and goats (Minka \& Ayo 2010). The decrease in blood pH and increase in lactate and peroxide caused by anaerobic exercise enhance EOF in horses (Hanzawa \& Watanabe 2000). Erythrocyte malondialdehyde (MDA) concentration has been shown to be a biomarker of lipid peroxidation (Belge, Cinar \& Selcuk 2003). Lipid peroxidation is the oxidative deterioration of polyunsaturated lipids, which leads to the production of a degraded product, called MDA (Belge et al. 2003). Lipid peroxidation has been shown to cause profound alterations in the structural organisation and function of cell membranes, including decreased membrane fluidity, increased membrane permeability, inactivation of membrane-bound enzymes and loss of essential fatty acids (Van Ginkel \& Sevanian 1994), resulting in membrane damage and cell death (Belge et al. 2003). Draper and Hadley (1990a) showed that production of MDA in vivo increases with exposure to environmental oxidants.

The use of donkeys as pack animals is cheap and affordable for the transportation of goods, including farm produce, by farmers in the rural areas to the markets. Packing and trekking donkeys over a long distance, which is a form of exercise, may alter the animals' physiological parameters, especially during the harmattan season, established to be the most thermally stressful season in the Northern Guinea Savannah zone of Nigeria (Ayo et al. 1998; Ayo, Obidi \& Rekwot 2011; Igono, Molokwu \& Aliu 1982). Exposure of animals to stress has been demonstrated to induce an increase in free radicals in the body. Vitamin C, also known as ascorbic acid (AA), is a potent antioxidant, shown to scavenge free radicals in the body (Belge et al. 2003; Urban-Chmiel et al. 2009). The possible oxidative effect of packing in donkeys is unknown, especially during the thermally stressful harmattan season.

There are three seasons in the northern Guinea savannah zone of Nigeria, the cold-dry (harmattan) (November-February), hot-dry (March-April) and rainy (May-October) seasons (Ayo et al. 2011; Igono et al. 1982). The harmattan season is characterised by a cold dust-laden wind, with low ambient temperature in the morning and evening hours of the day, but high ambient temperature during the day (Ayo et al. 1998; Moberg, Esu \& Malgwi 1991). 
The aim of the study was to investigate the effect of packing on EOF of donkeys, and the role of AA.

\section{Materials and methods \\ Experimental animals and management}

Twelve healthy pack donkeys comprising 6 males and 6 nonpregnant females, aged 3-4 years and weighing between $98 \mathrm{~kg}$ and $100 \mathrm{~kg}$ served as subjects. The donkeys were obtained from the donkey market at Sheme, about $10 \mathrm{~km}$ from Faskari $\left(11^{\circ} 43^{\prime} \mathrm{N}, 7^{\circ} 2^{\prime} \mathrm{E}\right)$, Nigeria. The donkeys were reared under traditional extensive management system without the provision of shelter (Minka \& Ayo 2007). They were in good body condition with a score of 7 (Pearson \& Ouassat 2000). The donkeys were fed with guinea corn straw and groundnut hay in the proportion of $4: 1$ and supplemented with wheat bran. In addition, $1 \mathrm{~kg}$ of whole sorghum grain was fed to each donkey per day throughout the experimental period. The donkeys were given access to water and salt-lick ad libitum during the experimental period.

\section{The study area}

The study was carried out during the harmattan season from 21st to 25th January, 2011. The study area covered an area from the Faculty of Veterinary Medicine, Ahmadu Bello University (ABU), Zaria $\left(11^{\circ} 10^{\prime} \mathrm{N}, 7^{\circ} 38^{\prime} \mathrm{E}\right)$ to Panhauya village $\left(11^{\circ} 7^{\prime} \mathrm{N}, 7^{\circ} 37^{\prime} \mathrm{E}\right)$, Kaduna State, located in the Northern Guinea Savannah zone of Nigeria. The donkeys covered a distance of $20 \mathrm{~km}$ (to and fro), from the Research Pen to Panhauya village on the outskirt of ABU, Zaria. The terrain of the route was narrow and stony, typical of the trekking route taken by pack donkeys in the zone.

\section{Administration of ascorbic acid}

The experimental animals $(n=6)$ were administered with AA (Sigma Chemicals, St. Louis, MO) orally and individually at $200 \mathrm{mg} / \mathrm{kg}$ (Chervyakov, Yevdokimov \& Vishker 1977; Snow, Gash \& Cornelius 1987), dissolved in $20 \mathrm{~mL}$ of sterile water. The control animals $(n=6)$ were given $20 \mathrm{~mL}$ of sterile water only. The administration was done by gavage $30 \mathrm{~min}$ before packing the donkeys on each day of the experiment.

\section{Packing procedure}

All the donkeys were saddled at 07h00 with a locally-made leather saddle pack frame, padded with chopped dry grasses to provide a cushion effect on the back of the animals. The saddles were loose enough to flap on both sides of the body of each donkey. Each donkey was subjected to work by packing it with sand, at the loading rate of $50 \%$ of live weight (Pal, Kumar \& Gupta 2002) at 10h00 on each experimental day. The loads were balanced evenly with similar weight bulk on either side of the animal, and padding was arranged such that it was thickest along sides of the backbone (Oudman 2004). The donkeys were used for work according to the standard procedure for packing as described by Pal et al. (2002). They were subjected to work for three days; for $4 \mathrm{~h}$ (from $10 \mathrm{~h} 00$ to 14h00) each day, and one day apart.

\section{Blood sample collection}

Blood was collected from the donkeys, pre-packing and post-packing at $06 \mathrm{~h} 00$ and $14 \mathrm{~h} 00$, respectively. Blood $(4 \mathrm{~mL})$ was aseptically collected from each donkey by jugular venipuncture, using a 10-mL syringe and 18-gauge sterile needles. The blood sample was divided into two $(2 \mathrm{~mL}$ each): one part with anticoagulant for EOF test, and the other without anticoagulant to extract serum samples for the determination of MDA concentration.

\section{Determination of erythrocyte osmotic fragility}

Erythrocyte osmotic fragility was determined in saline (Sodium Chloride [ $\mathrm{NaCl}]$ ) solutions as described by Oyewale et al. (2011). Briefly, $5 \mathrm{~mL}$ of varying concentration of each test solution of $\mathrm{NaCl}(0.1 \%, 0.3 \%, 0.5 \%, 0.7 \%, 0.9 \%)$ was prepared in a set each of 5 centrifuge tubes. Blood $(0.02 \mu \mathrm{L})$ was added to each concentration of the test solution in each tube. The contents were mixed and incubated at room temperature for $30 \mathrm{~min}$ and then centrifuged at $3000 \mathrm{~g}$ for $10 \mathrm{~min}$. The haemoglobin content of the supernatant was determined spectrophotometrically at a wavelength of $540 \mathrm{~nm}$ using the Bausch and Lomb spectrophotometer (FL Sales Inc. Grafton, Ohio, USA), with distilled water serving as blank. The percentage haemolysis in each concentration of $\mathrm{NaCl}$ was evaluated taking the tube with maximum haemolysis $(0 \%)$ as $100 \%$.

\section{Determination of serum malondialdehyde concentration}

The serum MDA was analysed using the method of Draper and Hadley (1990b). Briefly, $2.5 \mathrm{~mL}$ of $100 \mathrm{~g} / \mathrm{L}$ trichloroacetic acid solution was added to $0.5 \mathrm{~mL}$ serum in each centrifuge tube and placed in a boiling water bath for $15 \mathrm{~min}$. After cooling in tap water, the mixture was then centrifuged at $1000 \mathrm{~g}$ for $10 \mathrm{~min}$, and $2 \mathrm{~mL}$ of the supernatant was added to $1 \mathrm{~mL}$ of $6.7 \mathrm{~g} / \mathrm{L}$ thiobarbituric acid solution in a test tube and placed in a boiling water bath for $15 \mathrm{~min}$. The solution was then cooled in tap water and its absorbance measured using a ultraviolet (UV) spectrophotometer (T80+ UV/VIS Spectrometer, PG instruments Ltd., Alma Park, Wibtoft, Leicestershire, LE 175BE, UK) at $532 \mathrm{~nm}$. The concentration of MDA was calculated by the absorbance coefficient of MDATBA complex $\left(1.56 \times 10^{5} / \mathrm{cm}\right)$, and expressed in $\mu \mathrm{mol} / \mathrm{mL}$.

\section{Statistical analysis}

The data obtained were expressed as mean \pm standard error of the mean (Mean \pm SEM). Malondialdehyde data were subjected to one-way analysis of variance (ANOVA), followed by Tukey's multiple comparison post-hoc test, using GraphPad Prism 4.0 for Windows (GraphPad Software, San Diego, California, USA). The EOF data were subjected to Student's $t$-test to compare the differences between the means, obtained from the control and experimental donkeys. Values of $P<0.05$ were considered significant.

\section{Ethical considerations}

The handling, packing and trekking of the donkeys were carried out humanely in accordance with the guidelines, governing the welfare of research animals by the Ahmadu 
Bello University, and as approved by the Ethics Research Committee of the Department of Veterinary Physiology and Pharmacology, Ahmadu Bello University, Zaria under the permit number 5154 .

\section{Results}

\section{Erythrocyte osmotic fragility}

The results of EOF are shown in Figures 1 and 2. Pre-packing, the percentage haemolysis in the experimental group was not significantly $(P>0.05)$ different from values obtained in the control group at all the different $\mathrm{NaCl}$ concentrations (Figure 1). Post-packing, the percentage haemolysis in the experimental group was not significantly $(P>0.05)$ different from that of the control group at different $\mathrm{NaCl}$ concentrations, except at $0.3 \% \mathrm{NaCl}$ concentration. At $0.3 \%$ concentration, the percentage haemolysis of $93.69 \% \pm 2.21 \%$ obtained in the control donkeys was significantly $(P<0.05)$ higher than the value of $71.31 \% \pm 8.33 \%$, recorded in the experimental donkeys (Figure 2).

\section{Malondialdehyde concentration}

The changes in serum MDA concentration in the pack donkeys were also calculated (Figure 3). In the control donkeys, the pre-packing serum MDA concentration significantly $(P<0.05)$ rose from pre-packing value of $30.03 \mu \mathrm{mol} \pm 3.42 \mu \mathrm{mol}$ to post-packing value of $39.62 \mu \mathrm{mol} \pm 4.16 \mu \mathrm{mol}$. Similarly, in experimental donkeys MDA increased significantly $(P<0.05)$ from pre-packing value of $26.34 \mu \mathrm{mol} \pm 2.17 \mu \mathrm{mol}$ to postpacking value of $35.97 \mu \mathrm{mol} \pm 2.88 \mu \mathrm{mol}$. However, the post-packing MDA concentration of $39.62 \mu \mathrm{mol} \pm 4.16 \mu \mathrm{mol}$, obtained in the control donkeys was not significantly $(P>0.05)$ different from the value of $35.07 \mu \mathrm{mol} \pm 2.88 \mu \mathrm{mol}$ recorded in the experimental donkeys.

\section{Discussion}

The result of erythrocyte osmotic fragility showed that packing increased haemolysis in donkeys and the effect was more evident in the control than experimental donkeys. This agrees with the findings of Hesta et al. (2008), who showed that physical exertion increases haemolysis. The increased haemolysis obtained in the present study post-packing may be attributed to the effects of stress due to packing. This finding is in agreement with that obtained by Nazifi et al. 2009, who demonstrated that stress due to transportation induced oxidative stress resulting in an increase in the generation of free radicals. It has been established that erythrocytes are very susceptible to stress (Agrawal \& Sharma 2010; Altan et al. 2003; Vani, Shiva Shankar \& Asha Devi 2010). Therefore, the mitigation of packing-induced haemolysis by AA may be due to its antioxidant effect. Tauler et al. (2003) demonstrated that AA is capable of stabilising the integrity of cell membranes and decreasing its susceptibility to lipid peroxidation in exhaustive exercise, a form of stress. The result of the present study demonstrated for the first time that EOF may serve as a biomarker of stress due to packing in donkeys, and may be an important diagnostic tool for evaluating post-packing stress in donkeys.

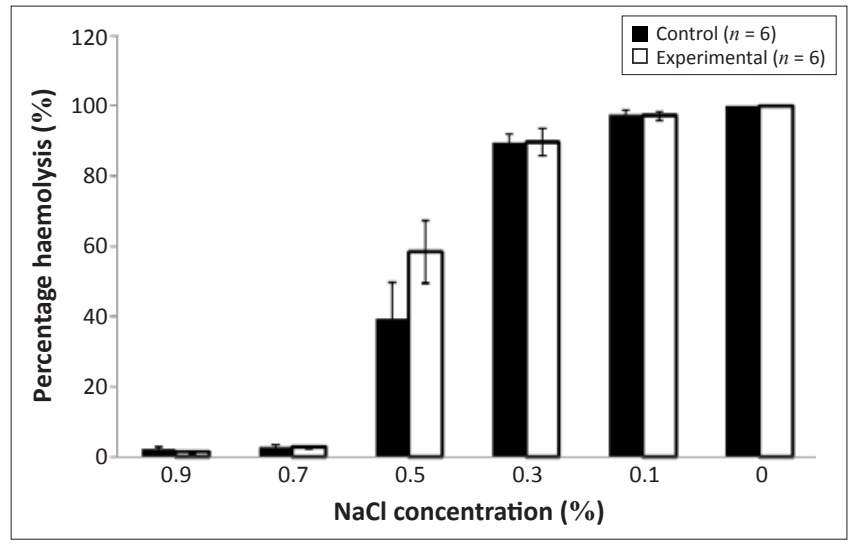

$\mathrm{NaCl}$, Sodium Chloride.

FIGURE 1: The erythrocyte osmotic fragility of the experimental and control donkeys pre-packing during the harmattan season.

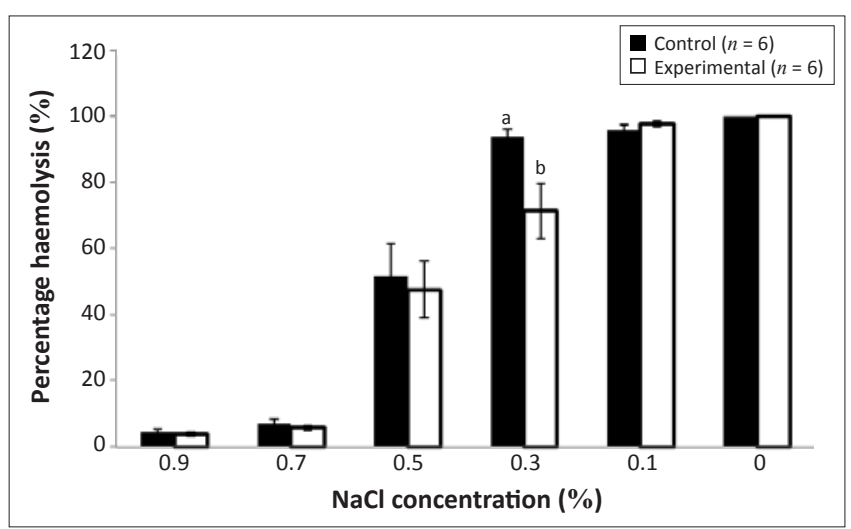

$\mathrm{NaCl}$, Sodium Chloride.

$a, b$, Values with error bars having different superscript letters are significantly $(P<0.05)$ different.

FIGURE 2: Effect of ascorbic acid on the erythrocyte osmotic fragility of donkeys subjected to packing during the harmattan season.

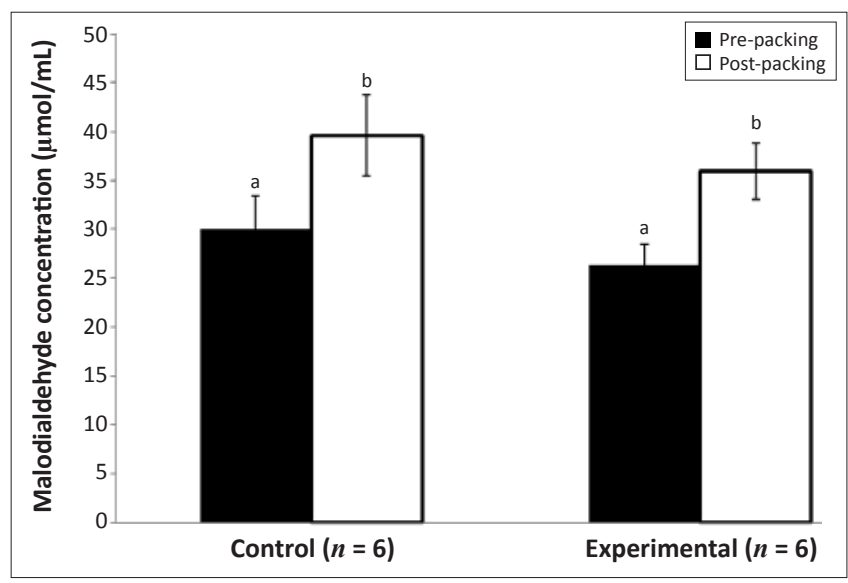

a,b, Values with error bars having different superscript letters are significantly $(P<0.05)$ different.

FIGURE 3: Changes in malonaldehyde concentration in donkeys subjected to packing during the harmattan season.

The increased MDA concentration obtained in the control donkeys and experimental donkeys after packing occurred, apparently, as a result of free-radical induced lipid peroxidation of the erythrocyte membranes, which impairs cell integrity and results in cell destruction (Hanzawa \& Wantanabe 2000; Jain 1986). There was no significant decrease in post-packing MDA concentration in the experimental 
donkeys when compared with that of control donkeys, indicating that AA did not ameliorate lipid peroxidation in donkeys, subjected to the packing. The result disagreed with previous findings that AA supplementation ameliorates oxidative damage due to heat stress in donkeys (Dey et al. 2010; Lin, Decuypere \& Buyse 2006), chemical-induced stress in mice (Ambali et al. 2010a, 2010b) and humans (Tauler et al. 2003), but agreed with the findings of Hesta et al. (2008) who reported that AA had no effect on thiobarbituric acid in dogs. However, in contrast to the finding of the present study, the dogs were not subjected to exercise. The result of MDA concentration obtained in the present study shows that EOF may be of better value in the determination of post-packing stress than MDA concentration, and may be a better biomarker of oxidative stress in donkeys subjected to packing. The finding of the present study also disagreed with the result of Aydemir et al. (2000) that AA strongly reduces MDA concentration in erythrocytes of chickens. The differences in the results may be due to species and especially the high resistance of donkeys to unfavourable environmental conditions (Fielding \& Krause 1998). Although AA has been shown to exert its antioxidative effect by removing singlet oxygen, hydroperoxyl, superoxide, lipid peroxyl and lipid free radicals (Belge et al. 2003), and thus decreases MDA concentration in animals subjected to stress, the packing regimen used in the present study was, apparently, not stressful enough to induce increased oxidative stress in the donkeys. The difference in the results obtained in the present study and those of other investigators may be due to the hardy nature and high adaptation of the donkey, the weather during which the study was carried out, and the short duration of work done by the pack donkeys. This requires further investigation.

\section{Conclusion}

Packing induced work stress in donkeys, resulting in an increase in haemolysis, which was ameliorated by AA administration. It is recommended that AA should be administered to donkeys before packing in order to ameliorate the adverse effects of work stress.

\section{Acknowledgements}

We wish to thank the team of reviewers for their tireless effort in improving the manuscript.

\section{Competing interests}

The authors declare that they have no financial or personal relationship(s) which may have inappropriately influenced them in writing this paper.

\section{Authors' contributions}

J.O.A. (Ahmadu Bello University) was the project leader responsible for experimental and project design and wrote the manuscript. S.F.A. (Ahmadu Bello University) and P.I.
(Ahmadu Bello University) made conceptual contributions. F.O. (Ahmadu Bello University) performed most of the experiments, prepared the samples, did the calculations and wrote the manuscript.

\section{References}

Adenkola, A.Y. \& Ayo, J.O., 2009, 'Effects of road transportation on erythrocyte osmotic fragility administered ascorbic acid during the harmattan season in Zaria, Nigeria', Journal of Cell and Animal Biology 3(1), 4-8. PMid:15590494

Adenkola, A.Y., Ayo, J.O., Sackey, A.K.B. \& Adelaiye, A.B., 2010, 'Erythrocyte osmotic fragility of pigs administered ascorbic acid and transported by road for short-term
duration during the harmattan season', African Journal of Biotechnology $9(2)$, duration $226-233$.

Agrawal, A. \& Sharma, B., 2010, 'Pesticides induced oxidative stress in mammalian systems: A review', International Journal of Biological and Medical Research 1(3), systems:

Altan, O., Pabuccuoglu, A., Koyanliogu, S. \& Bayrakta, H., 2003, 'Effect of heat stress on oxidative stress, lipid peroxidative and some stress parameters in broilers', British Poultry Science 44(4), 545-550.

Ambali, S.F., Akanbi, D., Shittu, M., Giwa, A., Oladipo, O.O. \& Ayo, J.O., 2010a, 'Chlorpyrifos-induced clinical, haematological and biochemical changes in Swiss albino mice: Mitigating effect by co-administration of vitamins $C$ and $E^{\prime}$, Life Science Journal 7(3), 37-44.

Ambali, S.F., Ayo, J.O., Ojo, S.A. \& Esievo, K.A.N., 2010b, 'Ameliorative effect of vitamin C on chronic chlorpyrifos-induced erythrocyte osmotic fragility in Wistar rats', Human and Experimental Toxicology 30(1), 19-24.

Asala, O.O., Ayo, J.O., Rekwot, P.I., Minka, N.S., Omoniwa, D.O. \& Adenkola, A.Y., 2011, 'Effect of ascorbic acid administration on erythrocyte osmotic fragility of pigs transported by road during the hot-dry season', Veterinary Research Communications 35(3), 245-254.

Aydemir, T., Ozturk, R., Bozkaya, L.A. \& Tarhan, L., 2000, 'Effects of antioxidant vitamins A, C, E and trace elements Cu, Se on CUZn SOD, GSH-Px, CAT and LPO levels in chicken erythrocytes', Cell Biochemistry and Function 18(2), 109-115.

Ayo, J.O., Obidi, J.A. \& Rekwot, P.I., 2011, 'Effects of heat stress on the well-being, fertility and hatchability of chickens in the northern Guinea savannah zone of Nigeria: A review', ISRN Veterinary Science Art. \#838606, 10 pages.

Ayo, J.O., Oladele, S.B., Fayomi, A., Jumbo, S.D. \& Hambolu, J.O., 1998, 'Body temperature, respiratory and heart rate in the red Sokoto goat during the harmattan season', Bulletin of Animal Health and Production in Africa 46(2), 161-166.

Belge, F., Cinar, A. \& Selcuk, M., 2003, 'Effects of stress produced by adrenocorticotropinon lipid peroxidation and some antioxidants in vitamin $C$ treated and non-treated chickens', South African Journal of Animal Science 33(3), 201-205.

Chervyakov, D.K., Yevdokimov, P.D. \& Vishker, A.S., 1977, Drugs in veterinary medicine, Kolos Publishing House, Moscow (in Russian).

Dey, S., Dwivedi, S.K., Malik, P., Panisup, A.S., Tandon, S.N. \& Singh, B.K., 2010 'Mortality associated with heat stress in donkeys in India', The Veterinary Record 166(5), 143-145.

Draper, H.H. \& Hadley, M., 1990a, 'A review of recent studies on the metabolism of exogenous and endogenous malondialdehyde', International Society for the Study of Xenobiotics 9(6), 901-907.

Draper, H.H. \& Hadley, M., 1990b, 'Malondialdehyde determination as index of lipid peroxidation', Method's in Enzymology 186, 421-431.

Fielding, D. \& Krause, P., 1998, The tropical agriculturist -Donkeys, Macmillan, London and Basingstoke.

Hanzawa, K. \& Wantanabe, S., 2000, 'Changes in osmotic fragility of erythrocytes during exercise in athletic horses', Journal of Equine Science 11(1), 51-61.

Hesta, M., Ottermans, C., Krammer-Lucas, S., Zentek, J., Helweg, P. \& Buyse, J., 2008 'The effect of vitamin C supplementation in healthy dogs on antioxidative capacity and immune parameters', Journal of Animal Physiology and Animal Nutrition 93(1), 26-34

Igono, M.O., Molokwu, E.C.I. \& Aliu, Y.O., 1982, 'Body temperature responses in savannah brown goats to the harmattan and hot-dry seasons', International Journal of Biometeorology 2(1), 225-230.

Jain, N.C., 1986, Schalm's veterinary haematology, 4th edn., Lea and Febiger, Philadelphia, viewed 23 June 2011, from http://books.google.com/books?isbn= 0683306928

Lin, H., Decuypere, E. \& Buyse, J., 2006, 'Acute heat stress induces oxidative stress in broilers', Comparative Biochemistry and Physiology 144(1), 11-17.

Minka, N.S. \& Ayo, J.O., 2007, 'Physiological responses of goats treated with ascorbic acid during the hot-dry season', Animal Science Journal 78(2), 164-172.

Minka, N.S. \& Ayo, J.O., 2010, 'Physiological responses of erythrocytes in goats to transportation and the modulatory role of ascorbic acid', Journal of Veterinary Medical Science 72(7), 875-881.

Moberg, J.P., Esu, I.E. \& Malgwi, W.B., 1991, 'Characteristics and constituent composition of harmattan dust falling in northern Nigeria', Geoderma 48(2), 73-81.

Nazifi, S., Saeb, M., Baghshani, H. \& Saeb, S., 2009, 'Influence of road transportation during hot-summer condition on oxidative status biomarkers in Iranian dromedarian camels (Camelus dromedarius)', African Journal of Biochemistry Research 3(7), 282-287. 
Oudman, L., 2004, Donkeys for traction and tillage, Digigrafi, Wageningen.

Oyewale, J.O., Dzenda, T., Yaqub, L., Akanbi, D., Ayo, J., Owoyele, O. et al., 2011 'Alterations in the osmotic fragility of camel and donkey erythrocytes caused by temperature, pH and storage', Veterinarski Arhiv 81(4), 459-470.

Pal, Y., Kumar, S. \& Gupta, A.K., 2002, 'Blood gases, acid-base and physiological indices in donkeys as pack animals', Draught Animal News 37(2), 27-33.

Pearson, R.A. \& Ouassat, M., 2000, A guide to liveweight estimation and body condition scoring of donkeys, Centre for Tropical Veterinary Medicine, University of Edinburgh, Edinburgh.

Snow, D.H., Gash, S.P. \& Cornelius, J., 1987, 'Oral administration of ascorbic acid to horses', Equine Veterinary Journal 19(2), 520-523.
Tauler, P., Aguilo, A., Gimeno, I., Fuentespina, E., Tur, J.A. \& Pons, A., 2003, 'Influence of vitamin $C$ diet supplementation on endogenous antioxidant defense during exhaustive exercise', European Journal of Physiology 446(6), 658-664.

Urban-Chmiel, R., Kankofer, M., Wernicki, A. \& Puchalski, A., 2009, 'The influence of different doses of $\alpha$-tocopherol and ascorbic acid on selected oxidative stress parameters in in vitro culture of leucocytes isolated from transported calves', Livestock Science 127(3), 365-370.

Van Ginkel, G. \& Sevanian, A., 1994, 'Lipid peroxidation induced membrane structural alterations', Methods in Enzymology 233, 273-288.

Vani, R., Shiva Shankar, R.C.S. \& Asha Devi, S., 2010, 'Oxidative stress in erythrocytes: A study of an effect of antioxidant mixtures during intermittent exposures to high altitude', International Journal of Biometeorology 54(5), 553-562. 